\title{
Buğday Bitkisine Uygulanan Farklı Miktarlarda Leonarditin Bazı Toprak Özelliklerine Etkisi
}

\author{
Betül KOLAY'* Songül GÜRSOY² Özlem AVȘAR' Nurettin BAYRAM ${ }^{1}$ \\ Ali Rıza ÖZTÜRKMEN ${ }^{3} \quad$ Salih AYDEMIR ${ }^{3}$ Hüsnü AKTAȘ ${ }^{4}$ \\ 'GAP Uluslararası Tarımsal Araștırma ve Eğitim Merkezi Müdürlüğü, Diyarbakır \\ ²Dicle Üniversitesi, Ziraat Fakültesi, Tarım Makinaları Bölümü, Diyarbakır \\ ${ }^{3}$ Harran Üniversitesi Ziraat Fakültesi, Toprak Bilimi ve Bitki Besleme Bölümü, Șanlıurfa \\ ${ }^{4}$ Artuklu Üniversitesi, Kızıltepe Meslek Yüksekokulu, Mardin
}

\begin{abstract}
*Sorumlu yazar e-posta (Corresponding author e-mail) : betul.kolay@tarim.gov.tr
Geliș tarihi (Received) : 16.06.2016

Kabul tarihi (Accepted) : 26.08.2016
\end{abstract}

\section{Öz}

Leonardit, toprak özelliklerini iyileștirmede ve dolayısıyla ürün verimini arttırmada kullanılan organik gübrelerden biridir. Bu çalıșmada, sulanabilir koșularda buğday bitkisine farklı miktarlarda leonardit uygulanarak, uygulanan bu leonarditin bazı toprak özellikleri üzerine olan etkisi belirlenmiștir. Çalıșma 2009-2012 yıllarında GAP Uluslararası Tarımsal Araștırma ve Eğitim Merkezi Müdürlüğü deneme alanında, tesadüf blokları deneme desenine göre dört tekerrürlü olarak yürütülmüștür. Denemede leonarditin 6 farklı dozu (0, 50, 100, 150, 200 ve $\left.250 \mathrm{~kg} \mathrm{da}^{-1}\right)$ uygulanmıștır. Hasat sonrası tüm parsellerde, toprakta organik madde, toprak nemi, hacim ağırlığı ve penetrasyon direnci belirlenmiștir. Çalıșma sonucunda, farklı miktarlarda uygulanan leonarditin toprakta organik madde, toprak nemi ve hacim ağırlığı üzerine etkisinin olmadığı, penetrasyon direnci üzerine etkili olduğu görülmüștür. Toprak penetrasyon direnci leonardit uygulaması ile azalmıștır.

Anahtar Kelimeler: Buğday, leonardit, toprak özellikleri

\section{Effect of Some Soil Properties of Different Doses Leonardite to Wheat}

\begin{abstract}
Leonardite is one of the organic fertilizer that used in development of soil characteristics and hence increase of yield. In this study the effects of different levels of leonardite were determined on some soil properties in irrigable conditions to wheat plant. The study was carried out between the years of 20092012 in the research area of GAP International Agricultural Research and Training Center as randomized complete blocks design with four replications. In this study six different levels at leonardite $10,50,100$, 150, 200, $250 \mathrm{~kg} \mathrm{da-1}$ ) were applied. Organic matter, soil moisture, bulk density and penetration resistance were determined in all plots after harvest. At the end of the study different levels of leonardite has no effect on organic matter, soil moisture, bulk density in soil and has effect on penetration resistance. Soil penetration resistance was decreased with leonardite application.
\end{abstract}

Key Words: Wheat, leonardite, soil properties 


\section{Giriș}

Güneydoğu Anadolu Bölgesi makarnalık buğdayın gen merkezidir (Kendal vd., 2012). Bölgede oldukça geniș alanlarda üretimi yapılmakta ve kaliteli makarnalık buğday elde edilmektedir.

Leonardit, eski çağlardan kalma bitki ve hayvan kalıntılarının okyanus, göl ve bataklık tabanlarında tortulașması sonucu olușan; yüksek basınç, sıcaklık ve anaerobik (oksijensiz) koșullarda materyalin (canlı atıklarının) bozunması ve humifikasyonu sonucu tabakalanmıș organik bir materyaldir (Özkan, 2007). Güneydoğu Anadolu Bölgesi'nde Adıyaman ilinde leonardit bulunmaktadır. Gıda Tarım ve Hayvancılık Bakanlığı'nın leonarditlerin gübre olarak kullanılabilirliği ile ilgili belirlemiș olduğu humik asit değerleri katı leonarditte toplam (hümik + fulvik) asit en az \% 40' dır (Engin vd., 2012). Yapılan bir çalıșma kapsamında, katı leonardit olarak Meriç, Adıyaman ve Denizli Bölgesi leonarditlerinin gübre olarak kullanılabileceği tespit edilmiștir (Engin vd., 2012). Ancak leonarditin toprak özellikleri ve bitki gelișimi üzerine olan etkisi ile ilgili Bölgede yapıımıș çalıșmalar çok azdır. Bu nedenle bu çalıșmada, organik madde içeriği yüksek olan ve Adıyaman yataklarından çıkarılmıș leonarditin bölgede çok yaygın olarak yetiștirilen makarnalık buğday bitkisinde toprak özellikleri üzerine olan etkisi belirlenmiștir.

\section{MATERYAL VE YÖNTEM}

Bu çalıșma, GAP Uluslararası Tarımsal Araștırma ve Eğitim Merkezi Müdürlüğü deneme alanında 2009-2012 yılları arasında yürütülmüștür.

\section{Araștırmada Kullanılan Leonarditin Özelliği}

Denemede Adıyaman Ilii leonardit yataklarımızdan çıkarılmıș ve piyasada satılan bir leonardit kullanılmıștır. Leonardite ait bazı özellikler Çizelge l'de verilmiștir.

Bu çalıșmada kullanılan leonarditin, 24.03.2014 sayılı Resmi Gazete'de “Tarımda Kullanılan Organik, Organomineral Gübreler ve Toprak Düzenleyiciler ile Mikrobiyal, Enzim İçerikli ve Organik Kaynaklı Diğer Ürünlerin Üretimi, İthalatı, İhracatı ve Piyasaya Arzına Dair Yönetmelik" kapsamında belirtilen ağır metal sınır değerlerinin altında olduğu tabloda görülmektedir. Aynı yönetmelikte humik+fulvik asit oranının en az \%40, $\mathrm{CaCO}_{3}$ oranının ise en fazla \% 8 olması gerektiği bildirilmiștir. Kullanılan leonardit bu özellikleri ile de uygundur. Leonarditin analizinde, ilgili yönetmeliğin EK-18 bölümünde belirtilen analiz metodları uygulanmıștır.

Araștırmada bitki materyali olarak bölgede yaygın olarak yetiștirilen ve GAP Uluslararası Tarımsal Araștırma ve Eğitim Merkezi tarafından tescil ettirilen Sarıçanak-98 buğday çeșidi kullanılmıștır. Bu çeșit, Güneydoğu Anadolu Bölgesi yağıșa dayalı ve sulu șartları (sulu șartlarda verimi yüksek) ile sahil bölgelerinde tavsiye edilebilir. GAPUTAEM (2016).

Her yıl farklı alanlarda olmak üzere deneme 3 yıl sürdürülmüștür. Denemenin kurulduğu alanlarda ekim öncesi alınan toprak örneklerinin bazı toprak özellikleri Çizelge 2'de verilmiștir.

Deneme konularını leonarditin $0 \mathrm{~kg} \mathrm{da}^{-1}, 50 \mathrm{~kg}$ $\mathrm{da}^{-1}, 100 \mathrm{~kg} \mathrm{da}^{-1}, 150 \mathrm{~kg} \mathrm{da}^{-1}, 200 \mathrm{~kg} \mathrm{da}^{-1}$ ve $250 \mathrm{~kg}$ $\mathrm{da}^{-1}$ olarak belirlenen altı farklı dozu olușturmuștur.

Çizelge 1. Denemede kullanılan leonardite ait bazı özellikler

Table 1. Some properties of leonardite using trial

\begin{tabular}{lcc}
\hline Incelenen Özellik & Analiz Sonucu & Ağır Metal Sınır Değerleri \\
\hline Organik Madde (kuru maddede \%) & 48,85 & \\
Toplam humik+fulvik asit (WNW, TSE 5869, \%) & 47,02 & \\
Toplam azot (N, Kjeldahl,\%) & 2,75 & \\
Toplam fosfor (P, Spektrofotometrik,\%) & 0,28 & \\
Toplam potasyum (K, Fleymfotometrik,\%) & 0,41 & \\
pH (1/10) & 6,16 & \\
EC (1/10, dS/m) & 4,80 & \\
Toplam CaCO, (Scheibler kalsimetresi, \%) & 2,01 & \\
Cu (bakı) (AAS, ppm) & 14,32 & 1100 \\
Zn (çinko) (AAS, ppm) & 578,79 & 120 \\
Ni (nikel) (AAS, ppm) & 69,17 & 3 \\
Cd (kadmiyum) (AAS, ppm) & $<0,036$ & 150 \\
Pb (kurșun) (AAS, ppm) & 20,16 & 350 \\
Cr (krom) (AAS, ppm) & 174,38 & 5 \\
Hg (civa) (AAS, ppm) & 4,28 & \\
\hline
\end{tabular}


Çizelge 2. Araștırmanın her 3 yılında ekim öncesi incelenen bazı toprak özellikleri

Table 2. Some soil properties examined every 3 years of the trial in before sowing

\begin{tabular}{lccc}
\hline İncelenen Toprak Özellikleri & Yıllar & 2.Yıl & $3 . Y_{\text {Il }}$ \\
\hline Bünye & 1.Yıl & $\mathrm{CL}$ & $\mathrm{CL}$ \\
$\mathrm{EC}(\mathrm{dS} / \mathrm{m})$ & $\mathrm{CL}$ & 0,85 & 0,24 \\
$\mathrm{PH}$ & 1,48 & 8,07 & 8,30 \\
$\mathrm{Kireç}(\%)$ & 7,78 & 12,00 & 14,29 \\
$\mathrm{P}_{2} \mathrm{O}_{5}\left(\mathrm{~kg} \mathrm{da}^{-1}\right)$ & 11,10 & 5,02 & 3,33 \\
Organik Madde $(\%)$ & 1,21 & 0,94 & 1,26 \\
Hacim Ağırlığı $\left(\mathrm{g} \mathrm{cm}^{-3}\right)$ & 0,84 & 1,25 & 1,47 \\
\hline
\end{tabular}

Belirlenen bu dozlar ekim öncesinde toprağa uygulanarak karıștırılmıștır. Çalıșma, tesadüf blokları deneme desenine göre 4 tekerrürlü olarak sulanabilir koșullarda yürütülmüștür. Bitkinin intiyaç duyduğu dönemlerde sulama yapılmıștır. Deneme 20092010, 2010-2011 ve 2011-2012 yetiștirme sezonunda 3 yıl süre ile yürütülmüștür.

Her yıl, hasattan hemen sonra tüm parsellerden bozulmuș ve bozulmamıș toprak örneği alınarak toprakta organik madde, toprak nemi ve hacim ağırlığı tespit edilmiștir. Organik madde miktarı modifiye Walkley- Black yaș yakma yöntemiyle (Richards, 1954) hacim ağırlığı Blake ve Hartge (1986)'ye göre belirlenmiștir. Hacim ağırlığı ve gravimetrik nem içeriği, $0-20 \mathrm{~cm}$ toprak derinliğinden $100 \mathrm{~cm}^{3}$ 'lük silindirlerle alınan bozulmamıș toprak örneklerini $105^{\circ} \mathrm{C}$ sıcaklıkta etüvde 24 saat bekletilerek belirlenmiștir. Toprağın penetrasyon direnci, elle itmeli maksimum $5 \mathrm{MPa}$ ve $80 \mathrm{~cm}$ derinlikte ölçüm yapabilen penetrometre aleti ile ölçülmüștür. Ölçümlerde taban alanı $2 \mathrm{~cm}^{2}$ olan konik uç kullanılmıștır. Penetrasyon direnci değerleri her bir parselde 10 farklı noktadan 20 cm toprak derinliğinden alınmıștır. Toprak organik maddesi ve toprak nemi \%, hacim ağırlığı $\mathrm{g} \mathrm{cm}^{-3}$ ve penetrasyon direnci kPa cinsinden belirlenmiștir.

\section{BULGULAR VE TARTIȘMA}

Toprağa farklı miktarda uygulanan leonarditin bazı toprak özellikleri üzerine olan etkisi Çizelge 3’de verilmiștir.

Çizelge 3 incelendiğinde organik madde, toprak nemi, hacim ağırlığı ve penetrasyon direnci değerlerinin yıllar arasında farklılık gösterdiği görülmüștür. Denemenin her 3 yılda da farklı alanda kurulmuș olması ve yıllar arasında yağıș ve sıcaklık gibi farklılıklar olmasından dolayı bu beklenen bir sonuçtur. Leonardit uygulamaları ile, organik madde, toprak nemi ve hacim ağırlığı parametreleri yönünden leonardit dozları arasında bir farklılık bulunmayıp, penetrasyon direnci parametresinde farklılık bulunmuștur. Leonardit uygulanmadığı zaman toprak penetrasyon direnci daha yüksek olurken, leonardit uygulaması ile penetrasyon direnci düșmüștür. Ancak 50, 100, 150, 200 ve $250 \mathrm{~kg} \mathrm{da}^{-1}$ leonardit dozları istatistiksel olarak aynı grupta yer almıștır.

Toprağa uygulanan leonardit ve humik maddenin toprakta incelenen özellikle kimyasal parametreler üzerine etkisinin kısa sürede görülmesi beklenmemektedir. Turgay vd., (2011) humik madde uygulamasının çalıșmalarının ilk yılında toprak organik madde miktarını arttırırken, ikinci yıl organik madde üzerine bir etkisinin olmadığını bildirmișlerdir. Demir vd., (2012) tarafından yapılan bir çalıșma sonucunda, leonarditin bir yıllık kullanımının toprak organik maddesini arttırmadığı bulunmuștur. Leonarditin fındıkta toprak düzenleyici olarak kullanıldığı bir çalıșma sonucunda, leonarditin bir yıllık kullanımının toprak organik maddesini arttırmadığı gözlenmiștir (Özyazıcı vd., 2010). Bu çalıșma, Demir vd., (2012) ve Özyazıcı vd., (2010) tarafından yapılan çalıșmalar ile paralellik göstermektedir. Çalıșmanın tüm uygulamalarında ölçülen organik madde miktarının, arzu edilen \%5 değerinin çok altında olduğu görülmektedir.

Alagöz vd. (2006)'e göre, değișik kökene sahip organik materyallerin düzenli ve etkin bir biçimde kullanılması ile toprakların bazı fiziksel ve kimyasal özelliklerinin iyileștirilebilmesi mümkündür. Deneme çakılı olarak yürütülmediği için, leonardit uygulamasının uzun yıllardaki etkisi değil, sadece bir yıllık kullanımının etkileri belirlenebilmiștir. Oğuz vd., (2012) tarafindan yapılan bir çalıșmada 100 kg da1 leonardit uygulaması ile biber yetiștirilen toprakta hacim ağırı̆̆ının değișmediği bildirilmiștir. Prasad ve Sinha (2000) tarafından en yüksek agregatlașmanın dengelenmiș organik gübre ve bitkisel atık uygulamaları ile elde edildiği ve bu sayede hacim ağırlığı ve penetrasyon direncinde bir azalma 
sağlandığı bildirilmiștir. Ferrini vd., (2005) leonarditin toprak iyileștirici olarak kullanılması ile toprak fiziksel özelliklerinin olumlu yönde etkilendiğini bildirmișlerdir. Leonardit uygulaması ile toprakta penetrasyon direnci kontrol ve gübrelemeye göre düșmüș, strüktür daha iyi gelișmiștir. Araștırmamızda toprak hacim ağırlığı açısından Oğuz vd., (2012) ile paralel, Prasad ve Sinha (2000) ile farklı sonuçlar bulunmuș olup; penetrasyon direnci açısından ise hem Prasad ve Sinha (2000) hem de Ferrini vd., (2005) ile benzer sonuçlar bulunmuștur.

Arslan (2006) penetrasyon direncinin buğday için 1,5 MPa olduğu, birçok bitki için bu değerin 22,5 MPa sınırına ulașmasının toprak sıkıșması ișareti olduğunun deneysel çalıșmalarla bulunduğunu bildirmiștir. Yapmıș olduğumuz bu çalıșmada hasat sonrası ölçülen penetrasyon direnci değerlerinin 2,5 MPa'dan yüksek olduğu görülmektedir.

Çizelge 3. Toprağa farklı miktarlarda uygulanan leonarditin toprakta organik madde, toprak nemi, hacim ağırlığı ve penetrasyon direnci üzerine etkisi

Table 3. The effect of leonardite applied to the soil in different quantity in soil organic matter, soil moisture, bulk density and penetration resistance

\begin{tabular}{|c|c|c|c|c|}
\hline \multirow[t]{2}{*}{ Leonardit Dozu } & \multicolumn{3}{|c|}{ Yıllar } & \multirow[t]{2}{*}{ Ortalama } \\
\hline & 1.Yıl & 2.YII & 3. YII & \\
\hline \multicolumn{5}{|c|}{ Organik Madde (\%) } \\
\hline 0 & 0,83 & 0,96 & 1,19 & 0,99 \\
\hline 50 & 0,60 & 0,90 & 1,48 & 0,99 \\
\hline 100 & 0,59 & 1,12 & 1,57 & 1,09 \\
\hline 150 & 1,05 & 0,95 & 1,45 & 1,15 \\
\hline 200 & 0,65 & 1,06 & 1,28 & 0,99 \\
\hline 250 & 0,60 & 1,00 & 1,30 & 0,96 \\
\hline Ortalama & $0,72 \mathrm{C}$ & $1,00 \mathrm{~B}$ & $1,38 \mathrm{~A}$ & \\
\hline CV & 27,18 & & & \\
\hline LSD & Yıl:0, 14** & & & \\
\hline \multicolumn{5}{|c|}{ Toprak Nem İçeriği (\%) } \\
\hline 0 & 10,80 & 10,03 & 15,19 & 12,01 \\
\hline 50 & 11,52 & 8,68 & 14,13 & 11,44 \\
\hline 100 & 10,36 & 10,41 & 13,80 & 11,52 \\
\hline 150 & 11,50 & 10,64 & 15,55 & 12,56 \\
\hline 200 & 10,57 & 12,63 & 14,21 & 12,47 \\
\hline 250 & 11,22 & 11,36 & 16,85 & 13,14 \\
\hline Ortalama & $10,99 \mathrm{~B}$ & $10,62 \mathrm{~B}$ & $14,95 \mathrm{~A}$ & \\
\hline CV & 17,30 & & & \\
\hline LSD & Yıl: $1,43^{* *}$ & & & \\
\hline \multicolumn{5}{|c|}{ Hacim Ağırlığı $\left(\mathrm{g} / \mathrm{cm}^{3}\right)$} \\
\hline 0 & 1,41 & 1,25 & 1,32 & 1,33 \\
\hline 50 & 1,35 & 1,30 & 1,31 & 1,32 \\
\hline 100 & 1,35 & 1,29 & 1,28 & 1,30 \\
\hline 150 & 1,50 & 1,30 & 1,29 & 1,36 \\
\hline 200 & 1,28 & 1,35 & 1,31 & 1,31 \\
\hline 250 & 1,53 & 1,26 & 1,25 & 1,35 \\
\hline Ortalama & $1,40 \mathrm{~A}$ & $1,29 \mathrm{~B}$ & $1,29 \mathrm{~B}$ & \\
\hline CV & 9,77 & & & \\
\hline LSD & Yıl:0,04** & & & \\
\hline \multicolumn{5}{|c|}{ Penetrasyon Direnci (kPa) } \\
\hline 0 & 4116,66 & 2512,66 & 3106,66 & $3245,33 A$ \\
\hline 50 & 2883,33 & 2593,33 & 3103,33 & $2860,00 \mathrm{~B}$ \\
\hline 100 & 3133,33 & 2523,33 & 3193,33 & $2950,00 \mathrm{~B}$ \\
\hline 150 & 3033,33 & 2640,00 & 2776,66 & $2816,67 \mathrm{~B}$ \\
\hline 200 & 3516,66 & 2476,66 & 2863,33 & $2952,22 \mathrm{~B}$ \\
\hline 250 & 2933,33 & 2646,66 & 2834,33 & $2804,78 \mathrm{~B}$ \\
\hline Ortalama & $3269,44 \mathrm{~A}$ & $2565,44 \mathrm{~B}$ & $2979,61 \mathrm{~A}$ & \\
\hline CV & 10,12 & & & \\
\hline LSD & YIl:294,82** & & & \\
\hline & Konu:286,17* & & & \\
\hline
\end{tabular}




\section{SONUC̣LAR}

Sonuç olarak, toprak organik maddesi, toprak nemi ve hacim ağırlığı leonardit uygulamaları ile değișmemiș, penetrasyon direnci leonardit uygulaması ile azalmıștır. Leonarditin kullanıldığı ilk yıllarda toprağın bazı fiziksel özelliklerini iyileștirdiği literatürlerde görülmektedir. Leonardit uygulaması ile toprak penetrasyon direncinin düșmesi, hasattan hemen sonra ölçülen yüksek penetrasyon direnci değerleri dikkate alındığında, olumlu bir sonuçtur. Bu, leonarditin toprak ıslahında kullanılabileceğini göstermektedir. Leonarditin uygun münavebe sistemleri içerisinde, uzun yıllar içerisinde toprağa ve bitki gelișimine olan etkisinin belirlenmesi gerektiği düșünülmektedir.

\section{KAYNAKLAR}

Alagöz Z, Yılmaz E, Öktüren F (2006). Organik materyal ilavesinin bazı fiziksel ve kimyasal toprak özellikleri üzerine etkileri, Akdeniz Üniversitesi Ziraat Fakültesi Dergisi, 19(2): 245254.

Arslan S (2006). Toprak sıkıșmasının azaltılması için alternatif bir yöntem: kontrollü tarla trafiği, Kahramanmaraș Sütçü İmam Üniversitesi Fen ve Mühendislik Dergisi, 9(1): 135-141.

Blake G R, Hartge K H (1986). Bulk density and particle density, In : Methods of soil analysis, Part I, Physical and mineralogical methods, ASA and SSSA Agronomy monograph No: 9 (2nd ed), Madison, Pp: 363-381.

Demir M, Noyan Ö F, Oğuz i (2012). Leonardit kullanımı ile birlikte azaltılmıș azotlu gübre uygulamalarının bitki verim ve toprak özellikleri üzerine etkileri, Sakarya Üniversitesi Fen Edebiyat Dergisi, 2012-1: 445-455.

Engin V T, Cöcen I, İnci U (2012). Türkiye'de leonardit, Sakarya Üniversitesi Fen Edebiyat Dergisi, 2012-1: 435-443.

Ferrini F, Giuntoli A, Nicese F P, Pellegrini S, Vignozzi N (2005). Effect of fertilization and backfill amendments on soil characteristics, growth, and leaf gas exchange of english oak (Quercus robur L.), Journal of Arboriculture 31:182-190.
GAPUTAEM (2016). Tescil Edilen Ceșitlerimiz Erișim:http://www.gaputaem.gov.tr

Kendal E, Tekdal S, Aktaș H, Karaman M (2012). Bazı Makarnalık Buğday Çeșitlerinin Diyarbakır ve Adıyaman Sulu Koșullarında Verim ve Kalite Parametreleri Yönünden Karșılaștırılması, Uludağ Ünv. Ziraat Fakültesi Dergisi, (26-1):114

Oğuz I, Noyan Ö F, Karaman M R, Koçyiğit R, Özen M (2012). Jalapeno Biber Tarımında Farklı Organik ve İnorganik Materyallerin Toprak Özellikleri ve Ürün Verimi Üzerine Etkilerinin Araștııılması, Sakarya Üniversitesi Fen Edebiyat Dergisi, 1: 393-403.

Özkan S (2007). Türk linyitlerinden humik asit ve gübre üretimi. Yüksek Lisans Tezi, Ankara Ünv. Fen Bilimleri Enstitüsü, Ankara.

Özyazıcı G, Özdemir O, Özyazıcı M A, Üstün G Y, Turan A (2010). Bazı organik materyallerin ve toprak düzenleyicilerin organik fındık yetiștiriciliğinde verim ve toprak özellikleri üzerine etkileri, Türkiye IV. Organik Tarım Sempozyumu, 28 Haziran-1 Temmuz, Erzurum.

Prasad B, Sinha S K (2000). Long-Term effects of fertilizer and organic manures on crop yields, nutrient balance and soil properties in rice-wheat cropping system in bihar. In: Abrol I P, Bronson K F, Duxbury J M, Gupta R K, (Eds.), In Long-Term Soil Fertility Experiments in Rice- Wheat Cropping Systems, RiceWheat Consortium Paper Series 6. New Delhi, Pp: 105-119

Richards LA (1954). Diagnosis and improvements of saline and alkaline soils. U.S. p. 160.

T.C. RESMi GAZETE (2014). Tarımda Kullanılan Organik, Organomineral Gübreler ve Toprak Düzenleyiciler ile Mikrobiyal, Enzim İçerikli ve Organik Kaynaklı Diğer Ürünlerin Üretimi, İthalatı, İhracatı Ve Piyasaya Arzına Dair Yönetmelik, 24.03.2014 Erișim: http://www.resmigazete.gov.tr

Turgay O C, Karaca A, Unver S, Tamer N (2011). Effects of coal- derived humic substance on some soil properties and bread wheat yield, Communications in Soil Science and Plant Analysis, 2011:42-9:1050:1070 